\title{
A vehicle stability control strategy with adaptive neural network sliding mode theory based on system uncertainty approximation
}

\author{
Xuewu $\mathrm{Ji}^{\mathrm{a}}$, Xiangkun $\mathrm{He}^{\mathrm{a}}$, Chen $\mathrm{Lv}^{\mathrm{b}}$, Yahui $\mathrm{Liu}^{\mathrm{a}}{ }^{*}, \mathrm{Jian} \mathrm{Wu}^{\mathrm{a}}$ \\ a State Key Laboratory of Automotive Safety and Energy, Tsinghua University, Beijing 100084, People's Republic of China \\ b Advanced Vehicle Engineering Center, Cranfield University, United Kingdom
}

\begin{abstract}
Modeling uncertainties, parameter variations and unknown external disturbances are the main obstacles in the development of advanced controller for vehicle stability control at the limits of handling. For the parameter variations and unknown external disturbances, sliding mode control (SMC) method could be employed to achieve satisfactory tracking performance. But modeling uncertainties, such as the errors are caused in the process of model simplification, always exist in the model-based controller design and degrade the control quality. The adaptive radial basis function network (ARBFN) can effectively improve the control performance against large uncertainty of the system by learning ability to approximate arbitrary nonlinear functions and guarantee the closed-loop system is robust global asymptotic stabilization. In this paper, a novel vehicle dynamics stability control strategy is proposed using adaptive radial basis function network sliding mode control (ARBFN-SMC) theory to learn the system uncertainties and eliminate the effects of system uncertainties. This strategy adopts a hierarchical control structure which consists of reference model layer, yaw moment control layer, braking torque allocation layer and executive layer. The co-simulation using MATLAB/Simulink and AMESim is conducted on a verified 15-DOF nonlinear vehicle system model with integrated-electro-hydraulic brake system (I-EHB) actuator under a Sine With Dwell manoeuvre. The simulation results show that the ARBFN-SMC scheme has superior stability and tracking performances at different running conditions compared with the SMC scheme.
\end{abstract}

Keywords: System uncertainty; Vehicle dynamics stability; Adaptive neural network; Sliding mode control; Extreme driving condition

\section{Introduction}

Active safety control systems are increasingly being applied to enhance the handling or stability performance of a vehicle [1-3]. Vehicle dynamics stability control system (VSC/ESC/ESP) can effectively prevent vehicle from spinning, drifting out and rolling over at the limits of handling [4]. VSC can generally be divided into three categories: VSC based on differential braking [3,5-10]; VSC based on active steering [11-13]; VSC through integration of two or more chassis control systems [14-16]. Of all these approaches, active brake control has received the most attention, because it can be easily realized, and VSC based on differential braking takes full advantage of the longitudinal force margin of the tire to generate active yaw moment to keep the vehicle stable under extreme driving maneuvers $[3,9,14]$.

Although the above research achievements were successful, there are still one of the main challenges for the vehicle dynamics stability control. System uncertainties, such as modeling uncertainties, parameter variations, unknown external disturbances, are ubiquitous in practical vehicle systems. If there is serious mismatch between model and plant or lateral tire force in this nonlinear region is treated as linear, the behaviors of the vehicle may be become uncontrollable and very dangerous, and then vehicle will lose stability and even turn over.

From the open-public literatures, though some researchers considered the system uncertainties in the controller design, most of the correlative researches fasten on parameter variations or external disturbances. As an important parameter in vehicle dynamics stability control system, tire cornering stiffness is affected by many factors (e.g. tire pressure, wheel alignment parameters, road condition, etc.), which is a disadvantage for vehicle motion control performance [14,17-20]. When the vehicle undergoes high accelerations at the limits of handling, tire's dynamics nature presents inherent nonlinearity that means a changed tire cornering stiffness. In [14], the variation of tire cornering stiffness is treated as the variation of the road adhesion coefficient. In [17,18], tire nonlinearity is handled using the uncertain tire cornering stiffness, which are represented via a norm-bounded uncertainty. In [19], the reduced nonlinear two track model and linear uncertain single track model with uncertainty of cornering stiffness have been established. In [20], an adaptive robust global chassis nonlinear controller is developed in order to deal with the parameter uncertainties in the vehicle system and the unknown external disturbances. In [21], tire cornering stiffness is obtained from the Burckhardt tire model, and unknown disturbance term is proposed.

As process of establishing and simplifying model will cause the modeling uncertainties, which complicates the development of high-performance closed-loop controllers, many nonlinear control methods and adaptive control schemes have been proposed for the uncertain nonlinear systems. In [22], an adaptive controller for a high-speed vehicle subject to modeling uncertainties is proposed. In [23], a robust integral of the sign of the error controller and an adaptive controller are synthesized to deal with modeling uncertainties via backstepping method for motion control of an electrohydraulic actuator. In [24], a sliding mode observer-based model reference adaptive controller is proposed for precise speed control of a permanent magnet DC motor in the presence of modeling uncertainties, friction and load variation. These adaptive controllers not only solved control problems in uncertain nonlinear systems successfully but also verified that adaptive control schemes can achieve better performance than conventional controllers.

However, most aforementioned method of handling the system uncertainties only considered the one or two types of the system uncertainties, and therefore this leads to some limitations. In fact, no matter how accurate the mathematical model and parameter identification are, it is extremely difficult to capture the exact system uncertainties to realize perfect compensation and tracking control [23]. The adaptive neural network can effectively improve the control performance against large uncertainty of 
the system by learning ability to approximate arbitrary nonlinear functions, and the adaptation law is derived using Lyapunov method so that the stability and the convergence of the entire system are guaranteed. Whereas the adaptive neural network in the nonlinear dynamical systems has the approximation errors, and vehicle dynamics stability control should have strong robustness. It is well known that the main advantage of using the SMC is good convergence and strong robustness with respect external disturbances [25,26]. But this type of controller is designed by assuming an exact mathematical model. Fortunately, as adaptive neural network sliding mode control based technique provides a potential tool for solving the control problems of highly uncertainties, strong disturbances, complex, nonlinear dynamics system [27,28].

In this paper, an ARBFN-SMC strategy based on system uncertainty approximation is proposed to improve the vehicle dynamics stability at the limits of handling. According to the controlled system, yaw moment control law is designed directly based on SMC principle using a non-linear vehicle model, which considers modeling uncertainties, parameter variations, unknown external disturbances. For unknown function item in yaw moment control controller, an adaptive learning method is proposed based on the ARBFN, which can approximate system uncertainties and guarantee the closed-loop system is robust global asymptotic stabilization.

Hierarchical control structure is adopted in the vehicle stability control scheme, as shown in Fig.1: the first layer is the identification and estimation layer, whose algorithm of estimating vehicle states and identifying tire-road information is as presented in [29-32]; as presented in Section 4.1, the second layer is the reference model layer which provides the desired vehicle dynamics states; as presented in Section 4.2, the third layer is the yaw moment control layer which includes the ARBFN-SMC based on system uncertainty approximation is employed to determine vehicle dynamics control efforts; as presented in Section 4.3, the fourth layer is the braking torque allocation layer which includes judging steering characteristic, deciding which wheel is controlled and executed braking torque regulation strategy; the last layer is the executive layer as presented in Section 4.4, where control strategy of I-EHB actuator is designed to adjust the wheel slip ratio, and then the suitable ground braking force can be generated.

The rest of this paper is organized as follows: a 15-DOF nonlinear vehicle model, magic formula (MF) tire model and the I-EHB actuator model are described in Section 2; the vehicle simulation model is verified in Section 3; the vehicle dynamics stability controller is illustrated in Section 4; the simulation results are shown in Section 5; Section 6 presents the conclusions of the paper.

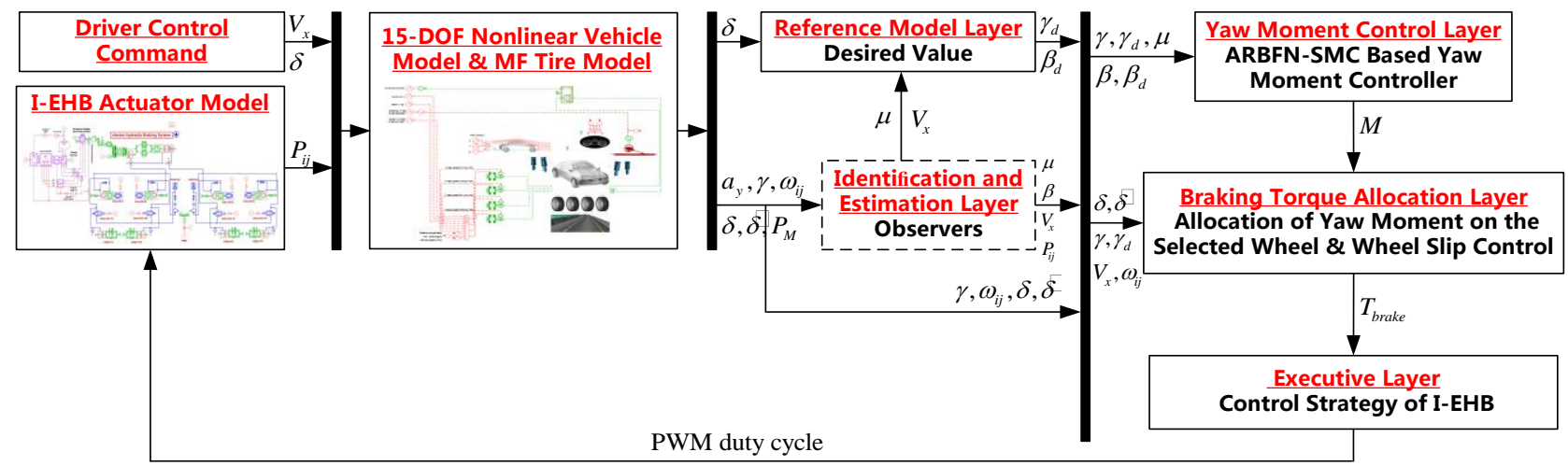

Fig.1. The control structure of the vehicle dynamics stability controller.

\section{System modelling}

\subsection{Vehicle model}

In order to fully reflect the state of vehicle dynamics, this paper adopted a more realistic vehicle system simulation model with vehicle dynamics iCAR application, standard signal and mechanical libraries in AMESim. The model presented here is a chassis system composed of a chassis model, central module for vehicle dynamics modeling (including axle kinematics and elastokinematics effects), with associated subsystems: suspension (spring, damper, lower and higher buffers, antiroll bar), aerodynamic, tire, road, sensors, powertrain unit, braking system and steering system. In the chassis model, the longitudinal displacement, the lateral displacement, the vertical displacement, the yaw rotation, the roll rotation and the pitch rotation of the sprung mass, the displacement of steering rack, the vertical displacements and the rotations of the four wheels are considered. The fifteen degrees of freedom of the vehicle system are depicted in Fig.2. 
Fig.2. Fifteen-degrees-of-freedom vehicle model.

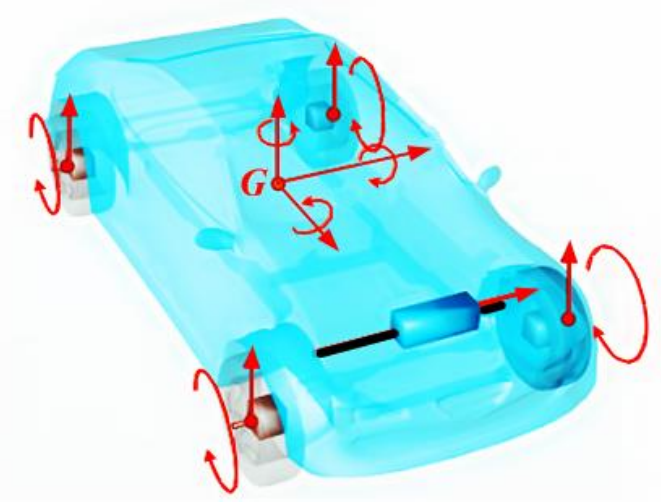

\subsection{Tyre model}

A non-linear tire model is used to describe the tire force because the process of vehicle stability control is highly dynamic. The Magic Formula (MF) tire model provides a precise tire dynamics in both linear and nonlinear region of tire. The general form of MF can be expressed as [33]:

$$
\begin{gathered}
y(x)=D \sin [C \arctan (\phi)] \\
\phi=B x-E[B x-\arctan (B x)] \\
Y(X)=y\left(X+S_{H}\right)+S_{v}
\end{gathered}
$$

where $Y$ represents the longitudinal force, the lateral force, or the aligning torque, and $X$ is the longitudinal slip ratio $\lambda$ or the wheel side-slip angle $\alpha$, which are defined as follows:

$$
\begin{gathered}
\lambda=-\frac{V_{s x}}{V_{x w}}=-\frac{V_{x w}-V_{r w}}{V_{x w}} \\
\alpha=\arctan \frac{V_{y w}}{V_{x w}} \\
V_{r w}=\omega r_{w}
\end{gathered}
$$

where $V_{r w}$ is the product of wheel rotation speed $\omega$ and wheel effective radius $r_{w}, V_{x w}, V_{y w}$ is the longitudinal and lateral speed of the wheel centre.

The parameters $B, C, D$ and $E$ are variable parameters for various vertical load based on empirical tire data. The factors are given as follows:

Factors of longitudinal force

Factors of lateral force

$$
\begin{aligned}
& C_{x}=b_{0} \\
& D_{x}=b_{1} F_{z}^{2}+b_{2} F_{z} \\
& B_{x}=\frac{\left(b_{3} F_{z}^{2}+b_{4} F_{z}\right) e^{\left(-b_{5} F_{z}\right)}}{C D} \\
& E_{x}=b_{6} F_{z}^{2}+b_{7} F_{z}+b_{8}
\end{aligned}
$$

where $F_{z}$ is the vertical load of tire, and the parameters $a_{0}-a_{9}, b_{0}-b_{9}$ and $c_{0}-c_{9}$ are illustrated in Table 1 .

Equations (7) and (8) show the calculation of tire force is related to the vertical load of each wheel. For vertical force, it will be transferred among four wheels while the vehicle is steering, driving and braking. Considering the longitudinal and lateral acceleration, the vertical load of each wheel can be calculated by [34]: 


$$
\begin{aligned}
& F_{z f l}=\left(g \frac{b}{2}-a_{x} \frac{h}{2}-a_{y} \frac{b h}{c}+a_{x} a_{y} \frac{h^{2}}{g c}\right) \frac{m}{L} \\
& F_{z f r}=\left(g \frac{b}{2}-a_{x} \frac{h}{2}+a_{y} \frac{b h}{c}-a_{x} a_{y} \frac{h^{2}}{g c}\right) \frac{m}{L} \\
& F_{z r l}=\left(g \frac{a}{2}+a_{x} \frac{h}{2}-a_{y} \frac{a h}{c}-a_{x} a_{y} \frac{h^{2}}{g c}\right) \frac{m}{L} \\
& F_{z r r}=\left(g \frac{a}{2}+a_{x} \frac{h}{2}+a_{y} \frac{a h}{c}+a_{x} a_{y} \frac{h^{2}}{g c}\right) \frac{m}{L}
\end{aligned}
$$

The longitudinal and lateral forces of tire need to satisfy the adhesion ellipse. Thus the lateral and longitudinal forces obtained by MF tire model need to be modified with the wheel slip angle and wheel slip ratio.

$$
\begin{gathered}
\sigma_{x}=\frac{\lambda}{1+\lambda}, \sigma_{y}=\frac{\tan \alpha}{1+\lambda} \\
\sigma=\sqrt{\delta_{x}^{2}+\delta_{y}^{2}} \\
F_{x}=\frac{\left|\sigma_{x}\right|}{\sigma} Y(X), F_{y}=\frac{\left|\sigma_{y}\right|}{\sigma} Y(X)
\end{gathered}
$$

Finally, the forces of tire, which have taken the load transfer, road friction coefficient, and combined-slip condition into consideration, can be calculated by Equations (1)-(11).

Table 1

Parameter values in the magic formula (Michelin ${ }^{\circledR}$ MXV8 205/55R16 91V).

\begin{tabular}{cccccccccc}
\hline$a_{0}$ & $a_{1}$ & $a_{2}$ & $a_{3}$ & $a_{4}$ & $a_{5}$ & $a_{6}$ & $a_{7}$ & $a_{8}$ & $a_{9}$ \\
1.6 & -34 & 1250 & 2320 & 12.8 & 0 & -0.0053 & 0.1925 & 0 & 0 \\
\hline$b_{0}$ & $b_{1}$ & $b_{2}$ & $b_{3}$ & $b_{4}$ & $b_{5}$ & $b_{6}$ & $b_{7}$ & $b_{8}$ & $b_{9}$ \\
1.55 & 0 & 1000 & 60 & 300 & 0.17 & 0 & 0 & 0.2 & 0 \\
\hline
\end{tabular}

\subsection{Structure and model of the I-EHB actuator}

The design of the I-EHB actuator adopted in this paper is shown in Fig.3. There are mainly electric brake master cylinder and eight high-speed on-off valves in the IEHB system, including a permanent magnetic synchronous motor 2 and a transmission 3 , four pressure increasing valves $(8,12,15,20)$ and four pressure reducing valves $(16,19,22,23)$. And there are two plunger pumps $(5,7)$. In addition, two accumulators $(17,21)$ are also used to store the brake fluid in pressure decreasing process to quickly reduce the wheel cylinder pressure.

When the vehicle is braking, motor 2 drives the transmission 3 forward or backward, which in turn pushes the piston of brake master cylinder to let brake fluid flow into four brake wheel cylinders through the eight solenoid valves regulating pressures respectively. When it needs to increase the pressures of one or a few wheel cylinders, motor 2 rotates clockwise, the piston of master cylinder moves forward, the corresponding pressure increasing valves open and pressure reducing valves close. When it needs to decrease the pressures of one or a few wheel cylinders, motor 2 rotates counter clockwise, the piston of master cylinder moves backward, the corresponding pressure reducing valves close and pressure increasing valves open, meanwhile the plunger pumps $(5,7)$ and the motor 6 work together auxiliarily reducing pressure. When it needs to maintain the pressures of one or a few wheel cylinders, motor 2 stalls, the corresponding valves close.

According to the engineering structure of the I-EHB actuator, this paper adopts the modular modeling method and builds an I-EHB simulation model in AMESim, as shown in Fig.4.

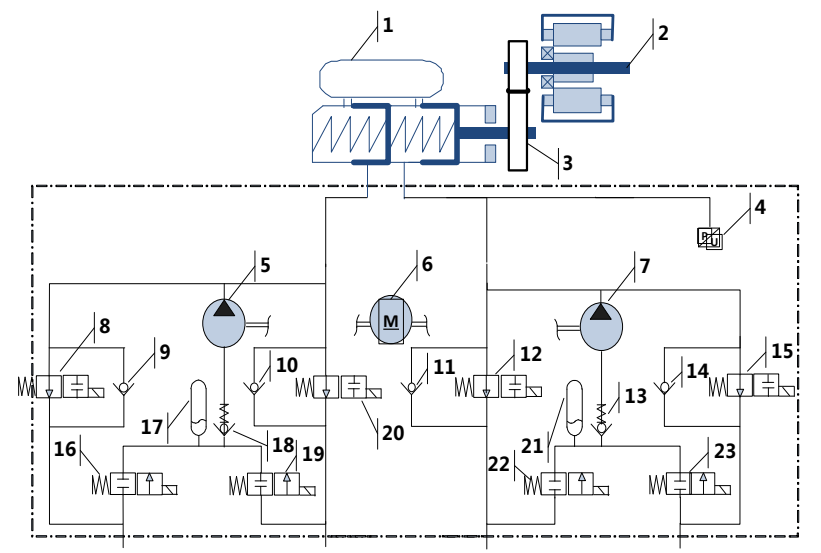


Fig.3. Structure of the I-EHB actuator.

1: fluid reservoir; 2,6: motor; 3: transmission; 4: pressure sensor; 5,7: pump; 8,12,15,20: pressure charging valve;9,10,11,13,14,18: check valve; 16,19,22,23: reducing valve; 17,21: accumulator.

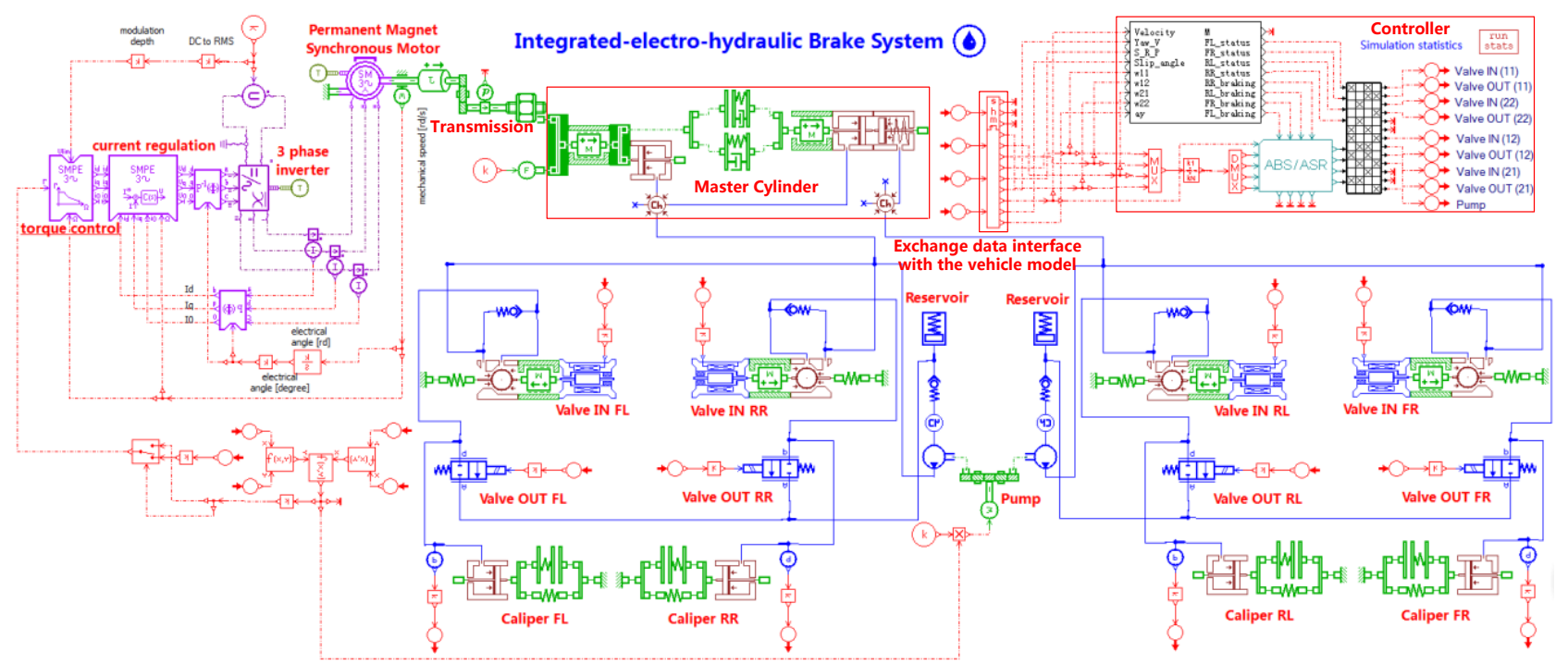

Fig.4. I-EHB actuator simulation model.

\section{Vehicle model verification}

Emergency steering manoeuvre at a high speed is liable to cause the vehicle spins out and even turns over, which is dangerous driving situation. Therefore, a simulation research scheme is adopted in this paper. However, the simulation model validation is an important part of the credibility of the simulation research and is quite significant.

In order to verify the accuracy and effectiveness of the vehicle model established, the simulation and test were carried out on the snow road. As shown in Fig.5, a Brilliance ${ }^{\circledR}$ vehicle was used to test, and the parameters of the vehicle are given in Table 2 (see Appendix). In simulations and test, the initial longitudinal velocity is $40 \mathrm{~km} / \mathrm{h}$, and the steering input signal is shown in Fig.6. The real yaw rate, lateral acceleration and sideslip angle of vehicle are measured by gyroscope, acceleration sensor and DGPS equipped on the test vehicle respectively, and comparisons of responses between experiment and simulation are shown in Fig.7. It can be seen that the responses of the experiment and the responses of the simulation are coincident approximately, and it indicates that the vehicle model is accurate and feasible.

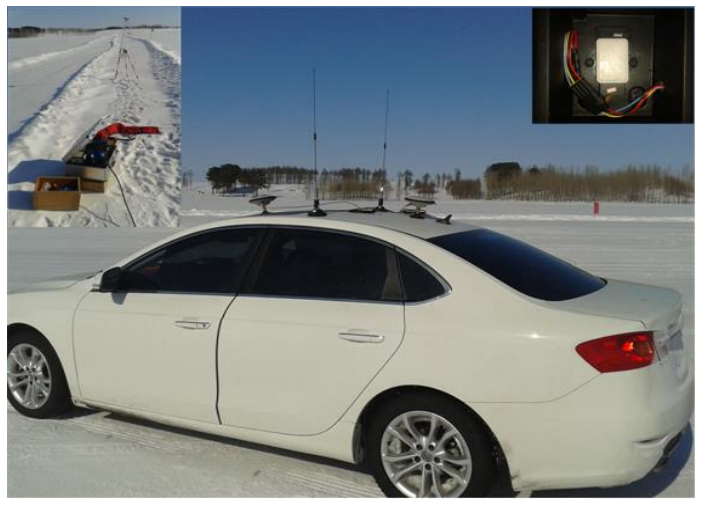

Fig.5. The test vehicle used for model verification.

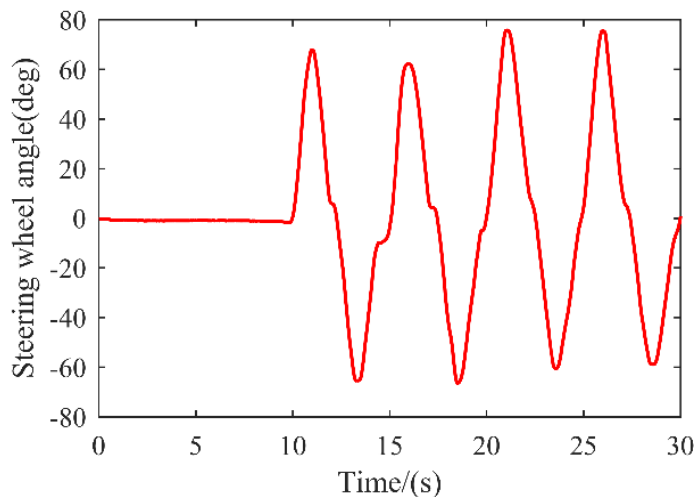

Fig.6. Steering wheel angle input. 

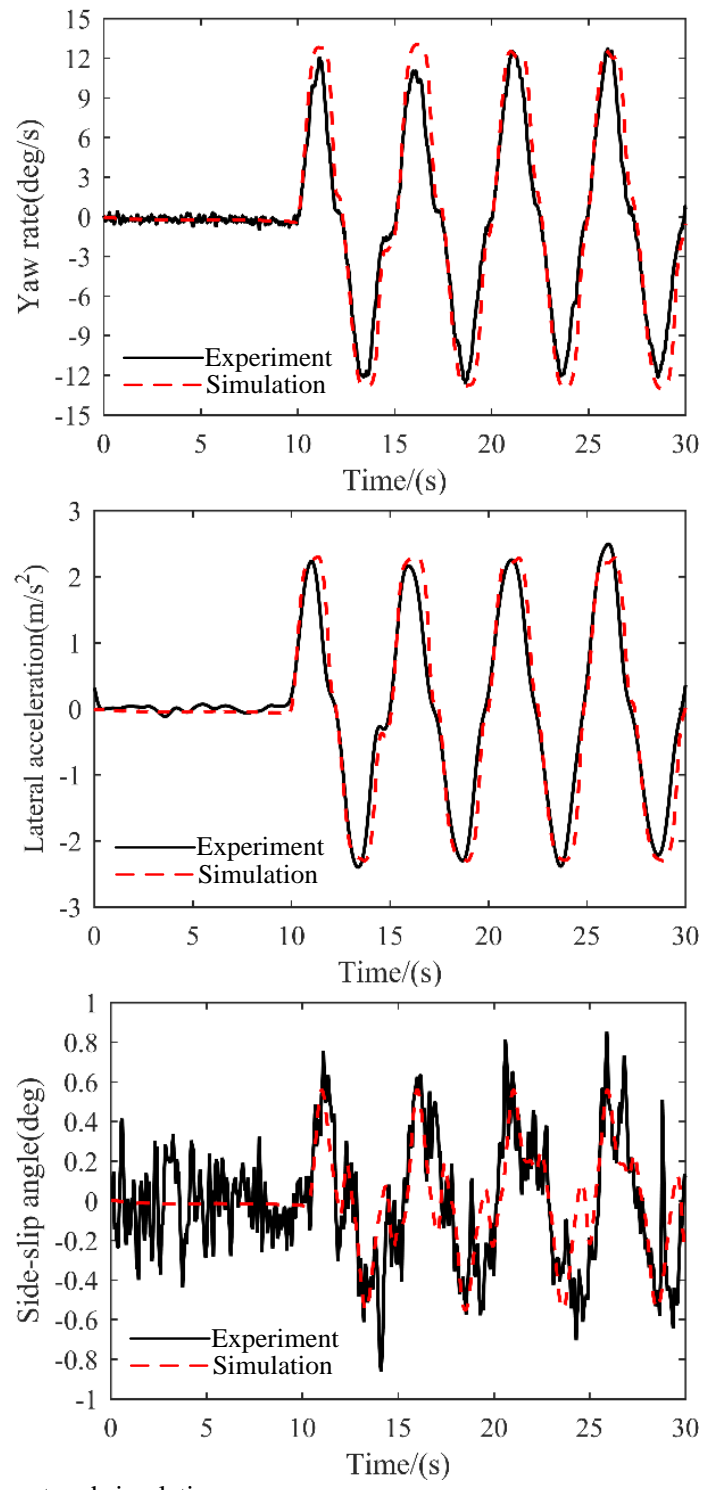

Fig.7. Comparisons of responses between experiment and simulation.

\section{Controller design}

\subsection{Reference model layer}

To design the vehicle stability controller, a widely used simplified the linear two-degrees-of-freedom vehicle model is considered to capture the essential vehicle lateral steering dynamics as follows:

with

$$
\&=A x+B u
$$

$$
\begin{aligned}
x & =\left[\begin{array}{ll}
\beta & \gamma
\end{array}\right]^{\mathrm{T}} \\
u & =\delta_{f} \\
A & =\left[\begin{array}{cc}
-\frac{C_{f}+C_{r}}{u m} & -\frac{a C_{f}-b C_{r}}{u^{2} m}-1 \\
-\frac{a C_{f}-b C_{r}}{J_{z}} & -\frac{a^{2} C_{f}+b^{2} C_{r}}{u J_{z}}
\end{array}\right] \\
B & =\left[\begin{array}{cc}
\frac{C_{f}}{u m} & \frac{C_{r}}{u m} \\
\frac{a C_{f}}{J_{z}} & -\frac{b C_{r}}{J_{z}}
\end{array}\right]
\end{aligned}
$$

where $\beta$ is sideslip angle of vehicle body, $\gamma$ is yaw rate of vehicle body, $\delta_{f}$ is front wheel steering angle, $m$ is the vehicle total 
mass, $u$ is the longitudinal velocity, $J_{z}$ is yaw moment of inertia, $a$ and $b$ are distance from the center of gravity to front and rear axle respectively, $C_{f}$ and $C_{r}$ in the above matrices are the cornering stiffnesses of the front-axle tires and the rear-axle tires respectively.

The yaw rate can be measured by a sensor but the sideslip angle is often estimated, which is not discussed here. About the sideslip angle estimation methods, the readers can refer to references [31,32]. Therefore, it is assumed that the sideslip angle can be obtained directly in this paper.

The desired handling and stability performance of the vehicle can be described by the desired sideslip angle $\beta_{d}$ and the desired yaw rate $\gamma_{d}$. In the procedure of controller design, however, for the consideration of convenience, the desired sideslip angle value is set to zero. And the linear 2-DOF vehicle model is used to get the yaw rate response; these are given by:

$$
\gamma_{d}=\frac{u /(a+b)}{1+u^{2} m\left(a C_{f}-b C_{r}\right) / C_{f} C_{r}(a+b)^{2}} \delta_{f}
$$

The desired yaw rate response cannot always be obtained when the tire force goes beyond the adhesion limit of the tire. Thus, an upper limit for the desired yaw rate can be given as follows [4]:

$$
\gamma_{d} \leq \frac{\mu g}{u}
$$

where $\mu$ is the road friction coefficient, $g$ is the acceleration due to gravity.

\subsection{Yaw moment control layer}

Model-based control strategy is subject to impaction of system uncertainties in practical applications, and they are inevitable problem in nature. Especially in critical driving condition (i.e., at the limits of handling), the vehicle is characterized by the strong nonlinearity and uncertainty, causing serious mismatch between the linear 2-DOF vehicle model and real vehicle. As a new intelligent control method, the ARBFN-SMC based on system uncertainty approximation technique provides an effective tool for solving the control problems of the strong nonlinear and uncertain dynamical systems. The controller is designed using the non-linear vehicle model, which is further expressed as:

$$
\begin{gathered}
{\left[\begin{array}{l}
\beta \approx \\
\alpha
\end{array}\right]=\left[\begin{array}{cc}
-\frac{C_{f}+C_{r}}{u m} & -\frac{a C_{f}-b C_{r}}{u^{2} m}-1 \\
-\frac{a C_{f}-b C_{r}}{J_{z}} & -\frac{a^{2} C_{f}+b^{2} C_{r}}{u J_{z}}
\end{array}\right]\left[\begin{array}{l}
\beta \\
\gamma
\end{array}\right]} \\
+\left[\begin{array}{cc}
\frac{C_{r}}{u m} & 0 \\
-\frac{C_{r} \cdot b}{J_{z}} & \frac{1}{J_{z}}
\end{array}\right]\left[\begin{array}{c}
0 \\
M_{e}
\end{array}\right]+\left[\begin{array}{l}
\frac{C_{f}}{m \cdot u} \\
\frac{a C_{f}}{J_{z}}
\end{array}\right] \delta_{f}+\left[\begin{array}{l}
\Delta_{1} \\
\Delta_{2}
\end{array}\right]
\end{gathered}
$$

where $M_{e}$ is the equivalent yaw moment, $\Delta_{1}$ and $\Delta_{2}$ are vehicle lateral motion uncertainty and vehicle yaw motion uncertainty respectively.

The objective of the yaw moment control layer is to determine the desired yaw moment for the vehicle so as to track the desired yaw rate and the desired sideslip angle. So define the error equations as follows:

$$
\begin{gathered}
e_{1}=\gamma-\gamma_{d} \\
e_{2}=\beta-\beta_{d}
\end{gathered}
$$

The sliding mode surface function is chosen so as to reduce the errors in the yaw rate and the sideslip angle with respect to the desired values, such that:

where $k$ is sliding mode factor.

$$
s=e_{1}+k e_{2}
$$

The sliding surface is defined as the state set when equation (19) equals to zero, that is $s=0$, so the following equation is derived:

$$
\&+k \&=0
$$

Combining equations (16) to (20) and differentiation of the sliding surface yield: 


$$
\begin{aligned}
& \&=\frac{M_{e}}{J_{z}}-\not \&-k \gamma \\
& -\left(\frac{a C_{f}-b C_{r}}{J_{z}}+k \frac{C_{f}+C_{r}}{u m}\right) \beta \\
& -\left(\frac{a^{2} C_{f}+b^{2} C_{r}}{u J_{z}}+k \frac{a C_{f}-b C_{r}}{u^{2} m}\right) \gamma \\
& +\left(\frac{a C_{f}}{J_{z}}+k \frac{C_{f}}{m \cdot u}\right) \delta_{f}+\Delta_{2}+k \Delta_{1}=0
\end{aligned}
$$

With Equation (21), the equivalent yaw moment $M_{e}$ can be described as:

$$
M_{e}=J_{z}(\not d+k \gamma-f)
$$

where

$$
\begin{aligned}
& f=-\left(\frac{a C_{f}-b C_{r}}{J_{z}}+k \frac{C_{f}+C_{r}}{u m}\right) \beta \\
& -\left(\frac{a^{2} C_{f}+b^{2} C_{r}}{u J_{z}}+k \frac{a C_{f}-b C_{r}}{u^{2} m}\right) \gamma \\
& +\left(\frac{a C_{f}}{J_{z}}+k \frac{C_{f}}{m \cdot u}\right) \delta_{f}+\Delta_{2}+k \Delta_{1}
\end{aligned}
$$

In order to make the system state stable on the sliding mode surface, a robust compensation term should be added to the equivalent control. The sliding mode robust compensation moment $M_{r c}$ is usually described as:

$$
M_{r c}=-q J_{z} \operatorname{sgn}(s)
$$

With the gain factor $q$, the system state can reach the sliding mode surface gradually and stabilize near the sliding mode surface. The gain factor $q$ is determined with the Lyapunov stability theory.

The total yaw control moment $M$ should be the sum of the equivalent control moment $M_{e}$ and the compensation moment $M_{r c}$, so it can be calculated according to equations (22) and (24) as follows:

$$
M=J_{z}[\chi \& d+k \gamma-f-q \operatorname{sgn}(s)]
$$

However, the tire cornering stiffness which is affected by many aspects, the vehicle yaw motion uncertainty and the vehicle lateral motion uncertainty are included in the equation (23), causing expression of the term $f$ difficult to be obtained. Therefore, the system uncertainty $f$ needs to be estimated. RBF neural network can be used to adaptively learn the system uncertainty $f$. The structure of RBF neural network is a three-layer feedforward network shown as in Fig.8. The input layer is the set of source nodes. The second layer is a hidden layer of high dimension. The output layer gives the response of the network to the activation patterns applied to the input layer [35]. In this paper, the advantage of RBF neural network is to approximate the system uncertainty $f$.

Fig.8. The adopted structure of RBF network.

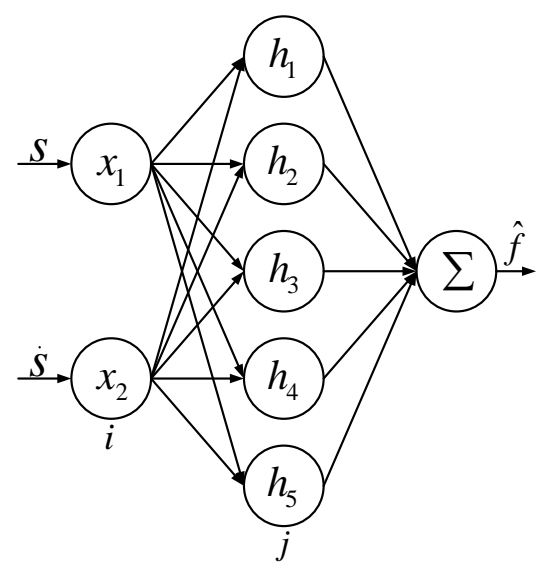

The algorithm of RBF network is:

$$
h_{j}=\exp \left(\frac{\left\|x-c_{j}\right\|^{2}}{2 b_{j}^{2}}\right)
$$




$$
\begin{gathered}
f=W^{* \mathrm{~T}} h(x)+\varepsilon \\
x=\left[\begin{array}{ll}
s & { }^{\mathrm{T}}
\end{array}\right.
\end{gathered}
$$

where $x$ is input of the network, $i$ is input number of the network, $j$ is the number of hidden layer nodes in the network, $h=\left[h_{j}\right]^{\mathrm{T}}$ is the output of Gaussian function, $c_{j}$ is the center vector of neural net $j, b_{j}$ represents the width value of Gaussian function for neural net $j, W^{*}$ is the ideal neural network weights, $\varepsilon$ is approximation error of the neural network, and $\varepsilon \leq \varepsilon_{\mathrm{N}}$.

Define the RBF neural network's learning indicator as:

$$
E=s \&
$$

According to gradient descent method, the learning algorithm of neural network weights (the base width vector, the center vector) can be obtained as follows:

$$
\begin{aligned}
& d b_{j}=-\rho \frac{\partial E}{\partial b_{j}}=-\rho s W_{j} h_{j} \frac{\left\|x-c_{j}\right\|^{2}}{b_{j}^{3}} \\
& b_{j}(t+1)=b_{j}(t)+d b_{j}+\zeta\left[b_{j}(t)-b_{j}(t-1)\right] \\
& d c_{i j}=-\rho \frac{\partial E}{\partial c_{i j}}=-\rho s W_{j} h_{j} \frac{x_{i}-c_{i j}}{b_{j}^{2}} \\
& c_{i j}(t+1)=c_{i j}(t)+d c_{i j}+\zeta\left[c_{i j}(t)-c_{i j}(t-1)\right]
\end{aligned}
$$

where $\rho \in(0,1)$ is the learning rate and $\zeta \in(0,1)$ is momentum factor.

Using the gradient descent method to design the weights adjustment law $W$ of RBF neural network, only local optimization can be guaranteed, the closed-loop system stability cannot be guaranteed, and the closed-loop system control is easy to diverge [36]. To solve this problem, there has been online adaptive neural network control method, the adaptive law is designed based on the Lyapunov stability theory, and the closed-loop system stability can be achieved. The approximation of the system uncertainty $f$ is:

$$
\hat{f}=\hat{W}^{\mathrm{T}} h(x)
$$

where $h(x)$ is the Gaussian function of RBF neural network.

Then the total yaw control moment (25) can be written as:

$$
M=J_{z}[x \&+k \gamma-\hat{f}-q \operatorname{sgn}(s)]
$$

The equivalent yaw moment $M_{e}$ is replaced with equation (33), equation (21) can be described as:

$$
\&=\frac{M}{J_{z}}-\& d z+k=f^{\prime}-q \operatorname{sgn}(s)
$$

where

$$
f \circ=f-\hat{f}=W^{\delta} h(x)+\varepsilon
$$

and $W^{0}=W^{*}-\hat{W}$.

Select the Lyapunov function as:

$$
V=\frac{1}{2} s^{2}+\frac{1}{2} \eta W^{\mathscr{\delta}} W^{\mathscr{C}}
$$

where the adaptive gain $\eta>0$.

Differentiating equation (36) results in:

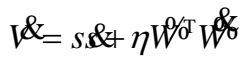

$$
\begin{aligned}
& =s[f \%-q \operatorname{sgn}(s)]-\eta W^{\delta} W^{\&} \\
& =s\left[W^{\mathscr{\delta}} h(x)+\varepsilon-q \operatorname{sgn}(s)\right]-\eta W^{\delta \delta} W^{\&} \\
& =W^{\otimes \delta}\left[\operatorname{sh}(x)-\eta W^{\&}\right]+s[\varepsilon-q \operatorname{sgn}(s)]
\end{aligned}
$$

Let adaptive law as:

$$
\stackrel{\&}{W}=\frac{1}{\eta} \operatorname{sh}(x)
$$

With equations (38), equation (37) can be changed as:

$$
I^{\&}=s[\varepsilon-q \operatorname{sgn}(s)]=\varepsilon s-q|s|
$$

Due to the approximation error $\varepsilon$ is limited and sufficiently small, selecting:

$$
q>|\varepsilon|
$$


Then the following inequation can be obtained:

in which case the system is stable.

$$
\mathbb{L}<0
$$

\subsection{Braking torque allocation layer}

The realization of selecting the controlled wheel and allocating the yaw moment can be achieved through an optimization course. Unfortunately, the computation is too complicated for a micro-controller. Therefore, the VSC controller often selects the most effective wheel to generate the yaw moment with the control based on slip ratio. When the vehicle is in oversteering, the front outer wheel is controlled as the prior wheel; while the vehicle is in understeering, the rear inner wheel is controlled as the prior wheel $[3,37]$.

\subsubsection{The selection of the controlled wheel}

The fundamental task of vehicle stability control system is to guarantee the stability of vehicle on the premise of satisfying the driver's driving intention. Therefore, the active braking intervention should not go against the driver's intention. The driver's steering intention (turn left or right) and the controlled vehicle steering characteristic (understeering or oversteering) must be judged according to the relevant information (steering wheel angle, steering wheel speed, yaw rate etc). The selection logic of the controlled wheel is illustrated in Appendix, Table 3. The desired braking control torque at the wheel is then computed as:

$$
T_{d b c}=M \operatorname{sgn}(M) \frac{R_{\text {roll }}}{B_{h t}}
$$

where $R_{\text {roll }}$ is tire rolling radius, and $B_{h t}$ is vehicle half-track.

\subsubsection{Wheel slip control}

In order to generate a proper braking force with the selected wheel, the wheel slip ratio is controlled, and the specific method is as follows:

(1) When the calculated tire longitudinal slip is lower than $S_{X A B S}(1+x)$, the regulation totally released the input brake torque down to zero. The output torque $T_{\text {brake }}$ with slip ratio control can be given as follows:

$$
T_{\text {brake }}=0
$$

(2) When the calculated tire longitudinal slip is in the regulation margin interval $\left[S_{X A B S}(1+x), S_{X A B S}(1-x)\right]$, the regulation released the input brake torque using simple linear function with respect to $S_{X}$. The output torque $T_{\text {brake }}$ with slip ratio control can be given as follows:

$$
T_{\text {brake }}=f\left(S_{X}\right)=\frac{T_{i n}}{2 x}\left[-\frac{S_{X}}{S_{X A B S}}+1+x\right]
$$

(3) When the calculated tire longitudinal slip is in the interval $\left[S_{X A B S}(1-x), 0\right]$, the desired braking control torque $T_{d b c}$ is applied. The output torque $T_{\text {brake }}$ with slip ratio control can be given as follows:

$$
T_{\text {brake }}=T_{d b c}
$$

where $T_{\text {brake }}$ is output brake torque with slip ratio control, $S_{x}$ is tire longitudinal slip, $S_{x A B S}$ is system longitudinal slip regulation value, $x$ is system regulation margin.

\subsection{Executive layer}

A resembling pulse width modulation (PWM) control method is adopted to convert the regulation information of the upper controller into the PMSM torque, the valve status (open/closed), and the hydraulic pump status (enabled/disabled). Moreover, the active safety system requires the actuator to respond quickly and accurately to the commands of the upper controller. Therefore, the control strategy for the I-EHB scheme in this paper is shown in Table 4.

Table 4

Control strategy of the I-EHB actuators.

\begin{tabular}{lllll}
\hline Modes & PMSM & Inlet valve & Outlet valve & Pump \& motor \\
\hline Default & 0 & 0 & 0 & 0 \\
Increase & $1.25 \mathrm{~N} \cdot \mathrm{m}$ & 0 & 0 & 0 \\
Retain & 0 & 1 (close) & 0 & 0 \\
Reduce & $-0.2 \mathrm{~N} \cdot \mathrm{m}$ & 1 (close) & 1 (open) & 1 (working) \\
\hline
\end{tabular}

(1) Pressure increasing mode

The target torque of PMSM is set as $1.25 \mathrm{~N} \cdot \mathrm{m}$, the target value of PWM duty cycle of corresponding inlet valves, that of corresponding outlet valves, and that of the pump motor are all set as 0 .

(2) Pressure retaining mode

All valves are closed to retain the fluid between inlet and outlet valves avoiding the pressure rising, and the PMSM stop working.

(3) Pressure reducing mode 
The target torque of the PMSM is set as $-0.2 \mathrm{~N} \cdot \mathrm{m}$, the corresponding inlet valves keep close and outlet valves keep open, meanwhile the oil pump and the pump motor auxiliarily reduce pressure.

\section{Simulation results and analysis}

The vehicle model is a mechanical system with low dynamic but with many algebraic calculations. On the contrary, the calculations of the braking system would probably be simpler but it is high dynamic because of electronical-hydaulic components. Therefore, the simulation model is divided into three parts running in co-simulation: the vehicle, the I-EHB actuator and vehicle stability controller. The vehicle model and the I-EHB actuator model are defined as master model and slave model respectively in the AMESim. The interface of controller in the slave model is connected to the Simulink model of the vehicle stability controller using adaptive RBFN sliding mode control based on system uncertainty approximation. Thus, the system modeling accuracy is much higher, and the division of calculations strongly accelerates the simulation which is very important for real time issues [38].

The relevant control information such as yaw rate, steering angle, wheel speeds, and so forth is sent by the vehicle model to the braking system in order to regulate the pressure in the hydraulic circuit. Depending on these variables, I-EHB system is activated or not. Then, the executive layer converts this binary information into valves status (open/closed) and pump status (disabled/enabled). At the end, the pressure in calipers can be reduced or intensified according to vehicle's behavior.

The main simulation parameters of the I-EHB actuator model are derived from Ref. [10].

For the RBF neural network, the initial parameters of the Gaussian function $b_{0}$ and $c_{0}$ are chosen as 1000 and $\left[\begin{array}{lllll}-2 & -1 & 0 & 1 & 2 \\ -5 & -2 & 0 & 2 & 5\end{array}\right]$, and the initial weight value is chosen as zero. In this paper, the other key parameters of the designed controller are shown in Appendix, Table 5.

According to the FMVSS 126 standard, longitudinal velocity at the beginning of the maneuver is $80 \mathrm{~km} / \mathrm{h}$, and the steering profile is a sine wave at $0.7 \mathrm{~Hz}$ frequency with a $0.5 \mathrm{~s}$ delay beginning at the second peak amplitude. From the above test scenario, all the dynamic characteristics of the vehicle can be adequately described, and the dynamics stability of the vehicle can be fully verified. Therefore, a Sine With Dwell maneuver referring to NHTSA FMVSS 126 standard is established in the AMESim.

\subsection{Test on a high adhesion-coefficient road}

The road surface is assumed to be flat and smooth with the adhesion coefficient of 1.0. In addition, the steering input signal for a Sine With Dwell maneuver is shown in Fig.9(a). Fig.9(b)-(f) shows the response comparisons from different points of view, including lateral dynamics, rolling dynamics, and longitudinal dynamics. As shown in Fig.9(b) and (c), although the ARBFN-SMC scheme and SMC scheme can both guarantee the stability of the vehicle, compared with the SMC scheme, the ARBFN-SMC scheme presents superior tracking performance to the reference response, and the uncontrolled vehicle will spin out or even turn over after about $4 \mathrm{~s}$. It can be found from Fig.9(d) and (e) that the roll angle and the lateral acceleration of the vehicle controlled by ARBFN-SMC have better dynamic performance than the SMC or no control. Under the premise that the vehicle should remain stable, the longitudinal velocity of the vehicle controlled by ARBFN-SMC would be less intervened by the braking control, as shown in Fig.9(f). The ARBFN-SMC controller can guarantee the stability of the vehicle by adjusting the selected wheel's brake pressure which is shown in Fig. $9(\mathrm{~g})$.

In order to explore the system uncertainty, a simplified estimation function of the system uncertainty is defined as:

$$
\begin{aligned}
& f_{e}=-\left(\frac{a C_{f}-b C_{r}}{J_{z}}+k \frac{C_{f}+C_{r}}{u m}\right) \beta \\
& -\left(\frac{a^{2} C_{f}+b^{2} C_{r}}{u J_{z}}+k \frac{a C_{f}-b C_{r}}{u^{2} m}\right) \gamma \\
& +\left(\frac{a C_{f}}{J_{z}}+k \frac{C_{f}}{m \cdot u}\right) \delta_{f}
\end{aligned}
$$

where all the parameters are given in Appendix, Table 5. Therefore, the uncertainty $\Delta_{1}+k \Delta_{2}$ can be approximately found with difference between equation (32) and equation (46). As shown in Fig.9(h), the red curve represents the approximation of the system uncertainty, and we can easily find that the variation of the system uncertainty, and it do not converge to zero; whereas the approximation of the system uncertainty is identical to the black curve (the uncertainty $\Delta_{1}+k \Delta_{2}$ ) after about $6 \mathrm{~s}$. Hence, it could be inferred that the modeling uncertainty plays a major role after about $6 \mathrm{~s}$. 


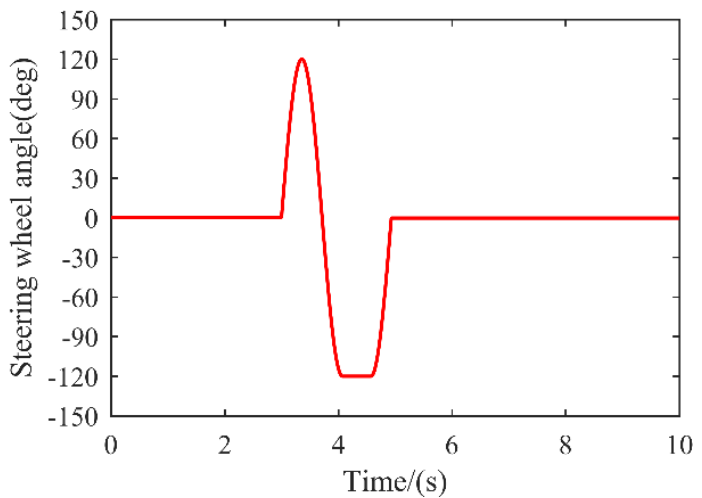

(a)

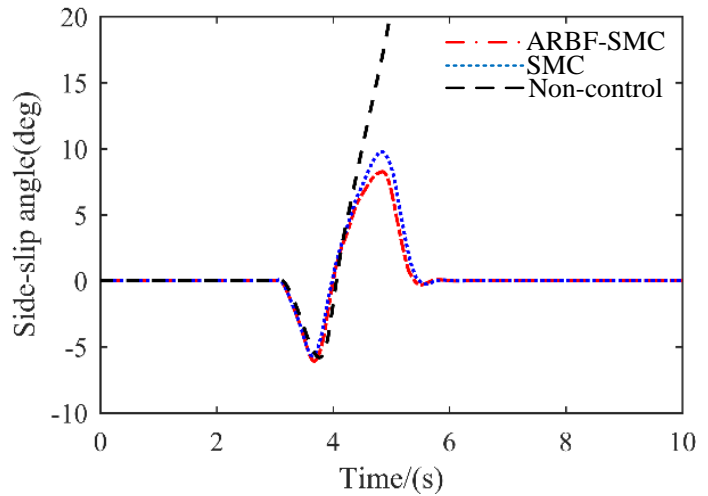

(c)

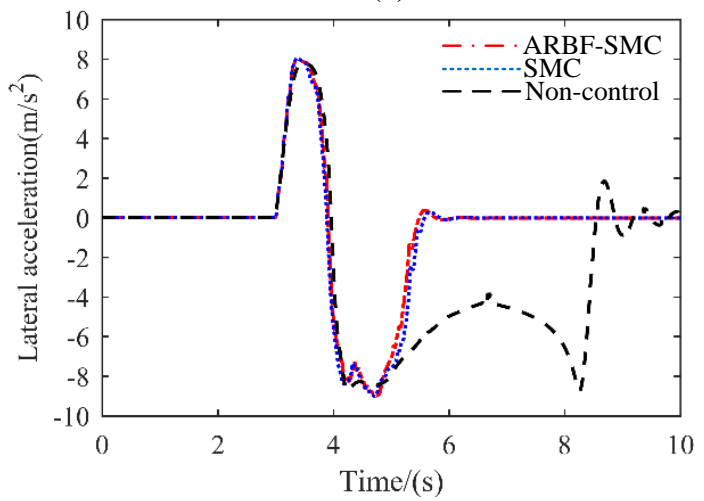

(e)

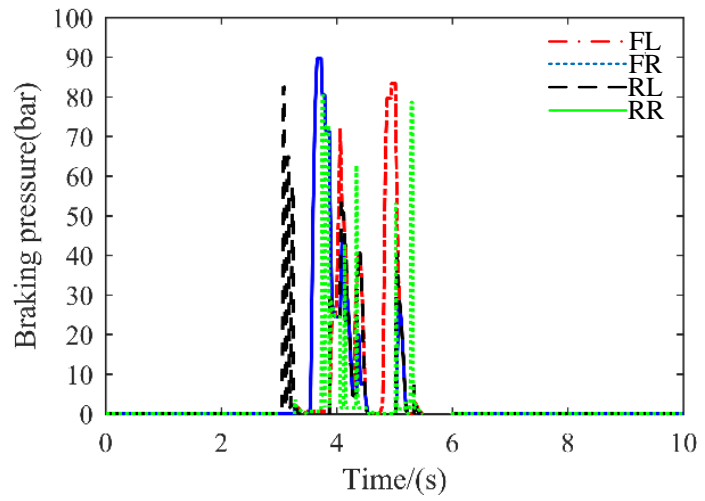

(g)

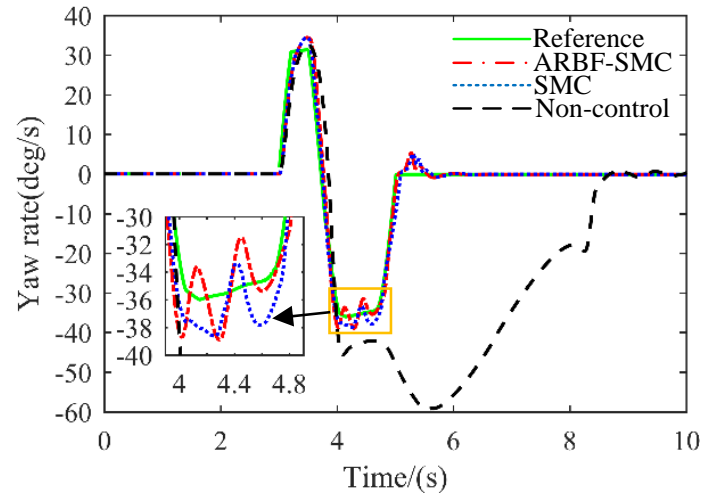

(b)

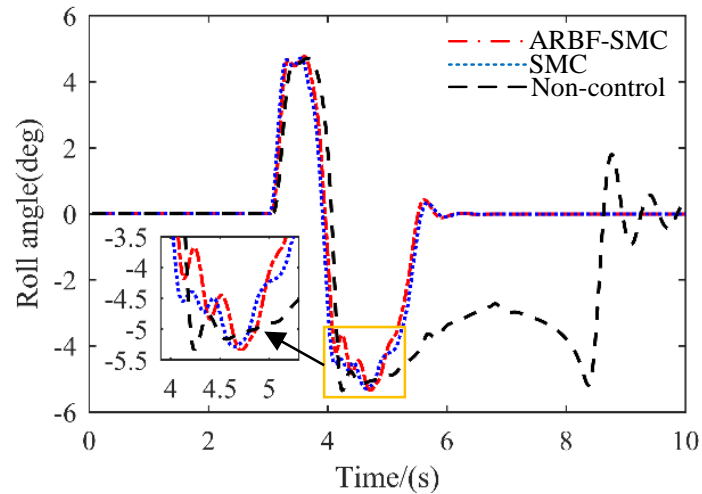

(d)

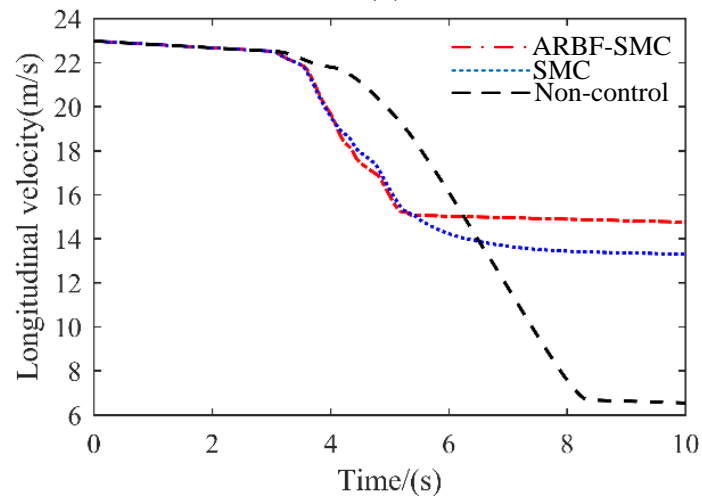

(f)

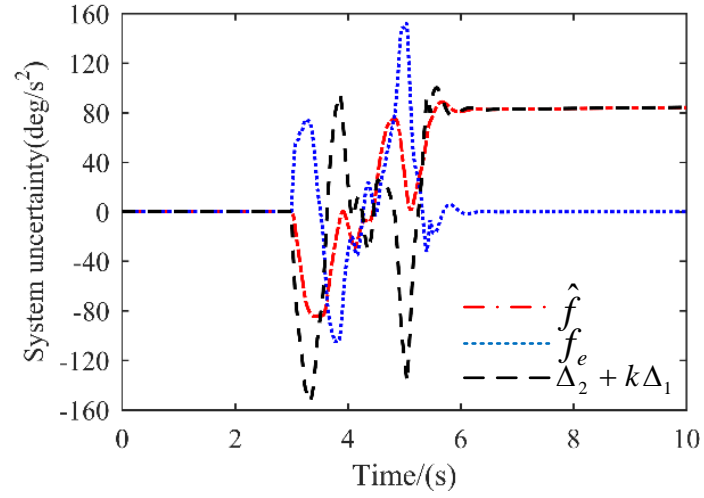

(h)

Fig.9. The results of the Sine With Dwell test on the high adhesion-coefficient road ( $\mu=1.0$ ). (a) Steering wheel angle input, (b) vehicle yaw rate, (c) vehicle side-slip angle, (d) vehicle body roll angle, (e) vehicle lateral acceleration, (f) vehicle longitudinal velocity, (g) brake pressure of the braking wheels by ARBFN-SMC controller, (h) system uncertainty.

\subsection{Test on a low adhesion-coefficient road}

In order to further evaluate the performance of the proposed ARBFN-SMC method, the vehicle system simulation model is running on an icy road with the adhesion coefficient of 0.15 through a Sine With Dwell maneuver with the steering input shown 
in Fig.9(a). It is observed that the ARBFN-SMC scheme is still stable and presents satisfying tracking performance to the reference model, as shown in Fig.10(a). Although the SMC scheme can also stabilize the lateral dynamics of the vehicle, its yaw rate tracking error is larger than the one of the proposed control scheme. As shown in Fig.10(a) and (b), the vehicle without control becomes unstable. It can be found from Fig.10(b) and (c) that the side-slip angle deviation and the lateral acceleration by the SMC controller shows more oscillations. Fig.10(d) illustrates that the rotating speed of the four wheels are controlled by ARBFN-SMC controller and the tires do not lock up. In addition, it could be inferred that the vehicle controlled by ARBFN-SMC spend more time for being in understeering state than oversteering. As shown in Fig.10(e), the red curve represents the approximation of the system uncertainty, and we can easily find that its peak value is the smallest, which means different categories of system uncertainty might appear to offset each other.

Equation (19) (the sliding mode surface function) is used as the stability indicator, which is shown in Fig.10(f). It can be seen that, the peak values of the sliding mode surface function by ARBFN-SMC controller, by SMC controller, and without the stabilizing controller are about 6.0, 9.2, and 12.6, respectively. Moreover, the ARBFN-SMC scheme has faster convergence speed and less oscillatory than the SMC scheme and without control. It can be explained that the running condition has deviated greatly on the low adhesion-coefficient road from that on the high adhesion-coefficient road where the controller is designed and the tire cornering stiffness has changed greatly, thus the difference caused severe model mismatch. Fortunately, the ARBFN-SMC scheme considers the system uncertainties, including the modeling uncertainty and the variation of the tire cornering stiffness, etc.
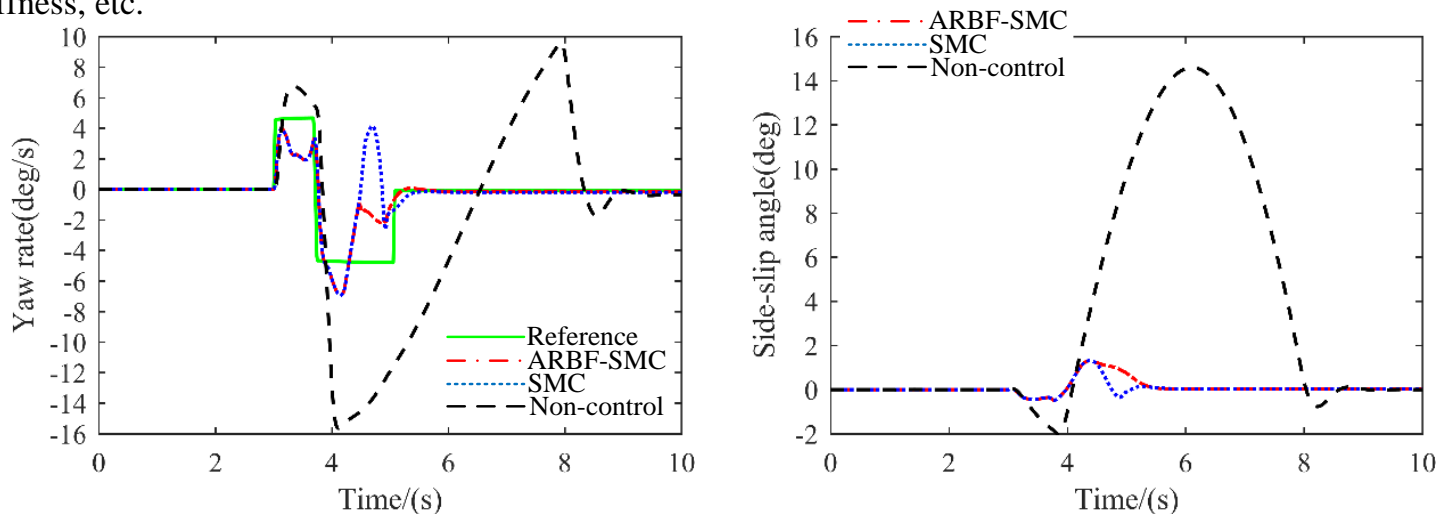

(a)
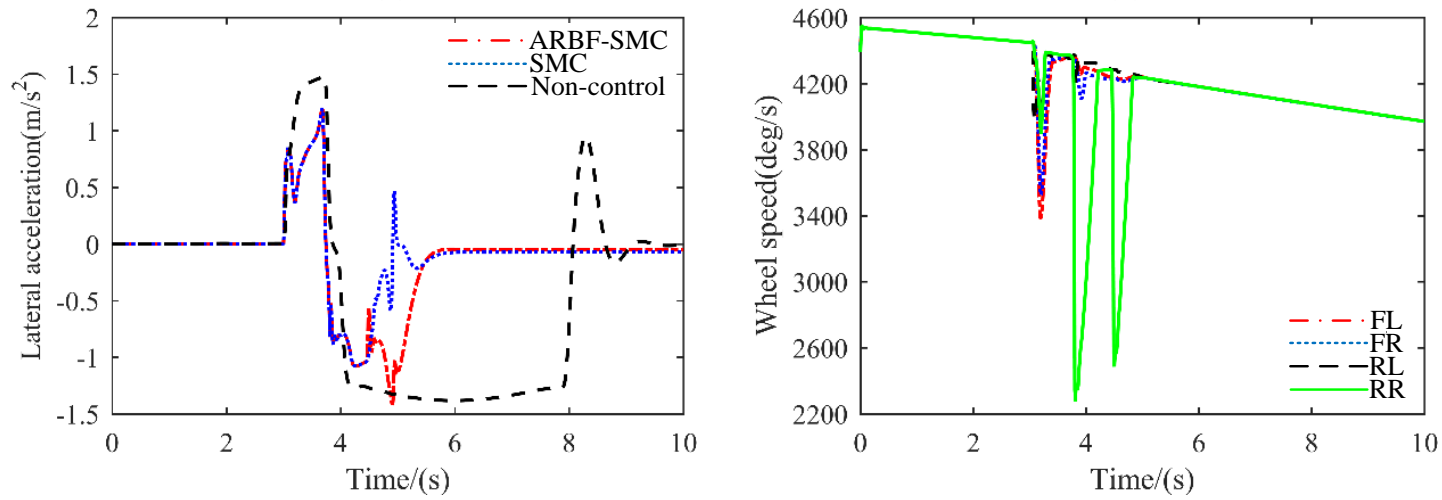

(c)

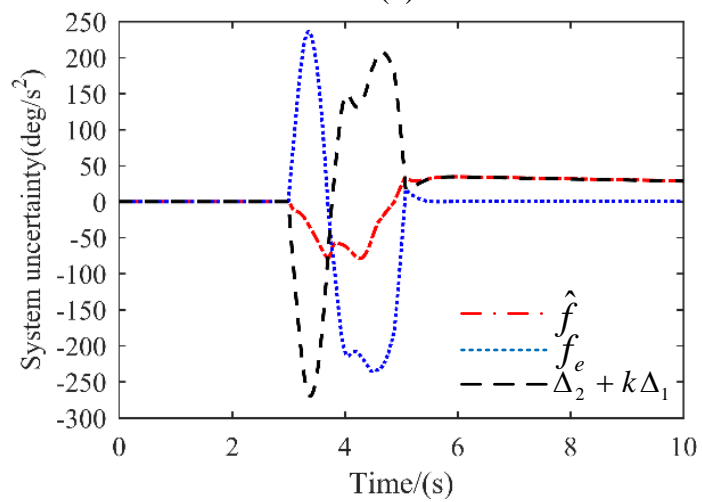

(e)

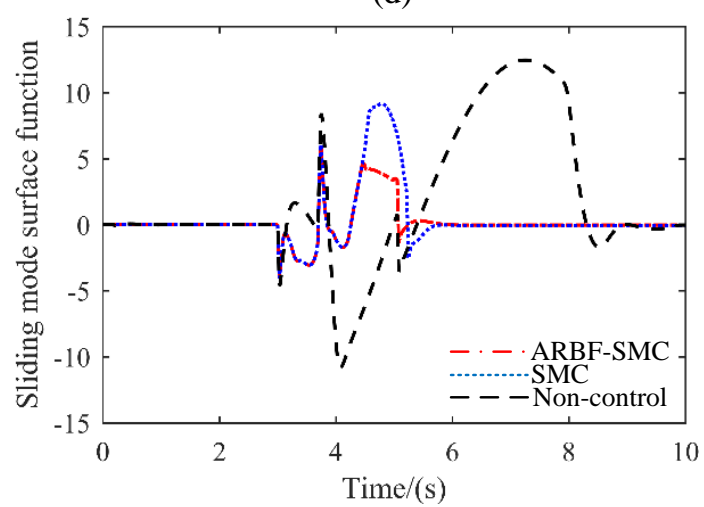

(f)

Fig.10. The results of the Sine With Dwell test on the low adhesion-coefficient road ( $\mu=0.15$ ). (a) Vehicle yaw rate, (b) vehicle side-slip angle, (c) vehicle lateral acceleration, (d) wheel speed by ARBFN-SMC controller, (e) system uncertainty, (f) sliding mode surface function. 


\section{Conclusion}

In this paper, an ARBFN-SMC strategy based on system uncertainty approximation is proposed to improve the vehicle stability at the limits of handling. Unlike the conventional SMC scheme which obviously oversimplifies the design of the vehicle dynamics stability controller because of the system uncertainty, the ARBFN-SMC scheme considers the modeling uncertainties, the variations of tire cornering stiffness, the unknown external disturbances.

The co-simulation is conducted on a verified 15-DOF nonlinear vehicle system model with I-EHB actuator for a Sine With Dwell manoeuvre to illustrate the effects of the ARBFN-SMC scheme by comparing with the responses of the SMC scheme and that of the passive vehicle. From the simulation results, we can find that when the vehicle is driving on the high adhesion-coefficient road $(\mu=1.0)$ at the limits of handling, the response difference of the two control schemes is small, while the difference becomes very large when the vehicle is driving on the low adhesion-coefficient road $(\mu=0.15)$ at the limits of handling, in which condition the ARBFN-SMC scheme is still stable and presenting good tracking performance to reference model, however, the SMC scheme will produce large tracing deviation. In other words, the change of running conditions has more influence on the SMC scheme.

In future work, the driver characteristic will be included and the effectiveness of ARBFN-SMC scheme will be evaluated in the driver-vehicle-road closed-loop system; in addition, the research in the future will consider multi-objects coordination equilibrium between vehicle stabilization and path tracking.

\section{Acknowledgments}

The authors greatly appreciate the support from the National Natural Science Foundation of China (grant numbers U1664263, 51375009), the Independent Research Program of Tsinghua University (grant number 20161080033), and the Natural Science Foundation of Shandong Province (grant numbers ZR2016EEQ06).

\section{Appendix}

The vehicle model is calibrated against the Brilliance ${ }^{\circledR}$ vehicle, and the parameters of the vehicle model are given in Table 2.

Table 2

Parameters of the vehicle model.

\begin{tabular}{|c|c|c|c|}
\hline Symbol & Parameter & Value & Units \\
\hline$m$ & Vehicle mass & 1430 & $\mathrm{~kg}$ \\
\hline$m_{s}$ & Vehicle sprung mass & 1300 & $\mathrm{~kg}$ \\
\hline$m_{u s}$ & Vehicle unsprung mass & 130 & $\mathrm{~kg}$ \\
\hline$a$ & Distance from front axle to gravity center & 1.056 & $\mathrm{~m}$ \\
\hline$b$ & Distance from rear axle to gravity center & 1.344 & $\mathrm{~m}$ \\
\hline$B_{f}, B_{r}$ & Track width of front and rear axle & 1.45 & $\mathrm{~m}$ \\
\hline$h_{c}$ & Height of gravity center & 0.375 & $\mathrm{~m}$ \\
\hline$I_{\text {sprung_xx }}$ & Moment of inertia of sprung mass - roll & 250 & $\mathrm{~kg} \mathrm{~m}^{2}$ \\
\hline$I_{\text {sprung_yy }}$ & Moment of inertia of sprung mass - pitch & 1000 & $\mathrm{~kg} \mathrm{~m}^{2}$ \\
\hline$I_{\text {sprung_zz }}$ & Moment of inertia of sprung mass - yaw & 1300 & $\mathrm{~kg} \mathrm{~m}^{2}$ \\
\hline$I_{\text {sprung_xy }}$ & Product of inertia of sprung mass - Ixy & 0 & $\mathrm{~kg} \mathrm{~m}^{2}$ \\
\hline$I_{\text {sprung_xz }}$ & Product of inertia of sprung mass - Ixz & -20 & $\mathrm{~kg} \mathrm{~m}^{2}$ \\
\hline$I_{\text {sprung_yz }}$ & Product of inertia of sprung mass - Iyz & 0 & $\mathrm{~kg} \mathrm{~m}^{2}$ \\
\hline$Z_{\text {ref_front }}, Z_{\text {ref__rear }}$ & $\mathrm{Z}$ ref suspension (front axle and rear axle) & 0.075 & $\mathrm{~m}$ \\
\hline$R_{\text {pinion }}$ & Radius of steering rack pinion & 0.008 & $\mathrm{~m}$ \\
\hline$K_{\text {susp_front }}$ & Suspension stiffness (front axle) & 21000 & $\mathrm{~N} / \mathrm{m}$ \\
\hline$K_{\text {susp_rear }}$ & Suspension stiffness (rear axle) & 21000 & $\mathrm{~N} / \mathrm{m}$ \\
\hline$R_{\text {susp_front }}$ & Suspension damping (front axle) & 2000 & $\mathrm{~N} /(\mathrm{m} / \mathrm{s})$ \\
\hline$R_{\text {susp_rear }}$ & Suspension damping (rear axle) & 1500 & $\mathrm{~N} /(\mathrm{m} / \mathrm{s}) \mathrm{s}$ \\
\hline$K_{\text {antiroll_front }}$ & Antiroll bar stiffness (front axle) & 30000 & $\mathrm{Nm} / \mathrm{rad}$ \\
\hline$K_{\text {antiroll_rear }}$ & Antiroll bar stiffness (rear axle) & 20000 & $\mathrm{Nm} / \mathrm{rad}$ \\
\hline$R_{\text {free }}$ & Free radius of the tire & 0.292 & $\mathrm{~m}$ \\
\hline$R_{\text {roll }}$ & Rolling radius of the tire & 0.29 & $\mathrm{~m}$ \\
\hline$R_{e f f}$ & Effective brake disc radius & 0.2 & $\mathrm{~m}$ \\
\hline$B_{f}$ & Brake pad/disc friction coefficient & 0.4 & null \\
\hline
\end{tabular}

3 .

Counter-clockwise is defined as the positive rotation, and the identification logic of the steer characteristic is shown in Table

\section{Table 3}


Steer characteristic identification logic.

\begin{tabular}{lllllll}
\hline Yaw control moment & Speed of steering & Steering angle & Driving direction & $\left|\mathrm{e}_{1}\right|$ & Steering character & Object of action \\
\hline+ & + & + & Left & $\geq 0.05 \mathrm{rad} / \mathrm{s}$ & Understeer & LR wheel \\
+ & + & - & Right & $\geq 0.05 \mathrm{rad} / \mathrm{s}$ & Oversteer & LF wheel \\
+ & + & 0 & Left & $\geq 0.05 \mathrm{rad} / \mathrm{s}$ & Understeer & LR wheel \\
+ & - & + & Left & & \\
+ & - & - & Right & $\geq 0.05 \mathrm{rad} / \mathrm{s}$ & Oversteer & LF wheel \\
+ & - & 0 & Right & $\geq 0.05 \mathrm{rad} / \mathrm{s}$ & Oversteer & LF wheel \\
+ & 0 & + & Left & $\geq 0.05 \mathrm{rad} / \mathrm{s}$ & Understeer & LR wheel \\
+ & 0 & - & Right & $\geq 0.05 \mathrm{rad} / \mathrm{s}$ & Oversteer & LF wheel \\
+ & 0 & 0 & Left & $\geq 0.05 \mathrm{rad} / \mathrm{s}$ & & LF wheel \\
- & + & + & Left & $\geq 0.05 \mathrm{rad} / \mathrm{s}$ & Oversteer & RF wheel \\
- & + & Right & & & \\
- & + & 0 & Left & $\geq 0.05 \mathrm{rad} / \mathrm{s}$ & Oversteer & RF wheel \\
- & + & Left & $\geq 0.05 \mathrm{rad} / \mathrm{s}$ & Oversteer & RF wheel \\
- & - & + & Right & $\geq 0.05 \mathrm{rad} / \mathrm{s}$ & Understeer & RR wheel \\
- & - & - & Right & $\geq 0.05 \mathrm{rad} / \mathrm{s}$ & Understeer & RR wheel \\
- & - & 0 & Left & $\geq 0.05 \mathrm{rad} / \mathrm{s}$ & Oversteer & RF wheel \\
- & 0 & + & Right & $\geq 0.05 \mathrm{rad} / \mathrm{s}$ & Understeer & RR wheel \\
\hline
\end{tabular}

The parameters of the controller are given in Table 5.

Table 5

Parameters of the controller.

\begin{tabular}{llll}
\hline Symbol & Parameters & Value & Units \\
\hline$a$ & Front wheelbase of reference model & 1.056 & $\mathrm{~m}$ \\
$b$ & Rear wheelbase of reference model & 1.344 & $\mathrm{~m}$ \\
$m$ & Mass of the vehicle of reference model & 1430 & $\mathrm{~kg}$ \\
$C_{f}, C_{r}$ & Front and rear tire cornering stiffness of reference model & 50000 & $\mathrm{~N} / \mathrm{rad}$ \\
$k$ & Sliding mode factor & 0.75 & $1 / \mathrm{s}$ \\
$q$ & Gain factor & 500 & $\mathrm{rad} / \mathrm{s}^{2}$ \\
$\rho$ & Learning rate & 0.05 & $\mathrm{null}$ \\
$\zeta$ & Momentum factor & 0.5 & $\mathrm{null}$ \\
$J_{z}$ & Yaw inertia & 1300 & $\mathrm{~kg} \mathrm{~m} \mathrm{~m}^{2}$ \\
$B_{T}$ & Vehicle half-track & 0.725 & $\mathrm{~m}$ \\
$R_{\text {roll }}$ & Tire rolling radius & 0.29 & $\mathrm{~m}$ \\
$S_{X_{f}}$ & Longitudinal slip regulation value - front axle & $-12 \%$ & $\mathrm{null}$ \\
$x_{f}$ & Regulation margin - front axle & $20 \%$ & $\mathrm{null}$ \\
$S_{X_{-} r}$ & Longitudinal slip regulation value - rear axle & $-8 \%$ & $\mathrm{null}$ \\
$x_{r}$ & Regulation margin - rear axle & $20 \%$ & $\mathrm{null}$ \\
\hline
\end{tabular}

\section{References}

[1] Di Cairano S, Tseng H E, Bernardini D, et al. Vehicle yaw stability control by coordinated active front steering and differential braking in the tire sideslip angles domain. IEEE Transactions on Control Systems Technology 2013; 21(4): 1236-1248.

[2] Wang $\mathrm{F}$, Chen $\mathrm{H}$, Guo H, et al. Constrained $\mathrm{H}_{\infty}$ control for road vehicles after a tire blow-out. Mechatronics 2015; 30: 371-382.

[3] Li L, Jia G, Chen J, et al. A novel vehicle dynamics stability control algorithm based on the hierarchical strategy with constrain of nonlinear tyre forces. Vehicle System Dynamics 2015; 53(8): 1093-1116.

[4] Rajamani R. Vehicle dynamics and control. Springer Science \& Business Media; 2011.

[5] Yi K, Chung T, Kim J, et al. An investigation into differential braking strategies for vehicle stability control. Proceedings of the Institution of Mechanical Engineers, Part D: Journal of Automobile Engineering 2003; 217(12): 1081-1093.

[6] Barbarisi O, Palmieri G, Scala S, et al. LTV-MPC for Yaw Rate Control and Side Slip Control with Dynamically Constrained Differential Braking. European Journal of Control 2009; 15(3-4):468-479.

[7] Zong C, Zhu T, Wang C, et al. Multi-objective Stability Control Algorithm of Heavy Tractor Semi-trailer Based on Differential Braking. Chinese Journal of Mechanical Engineering 2012; 25(1):88-97.

[8] Tchamna R, Youn I. Yaw rate and side-slip control considering vehicle longitudinal dynamics. International Journal of Automotive Technology 2013; 14(1): 53-60.

[9] Li L, Lu Y, Wang R, et al. A 3-Dimentional Dynamics Control Framework of Vehicle Lateral Stability and Rollover Prevention via Active Braking with MPC. IEEE Transactions on Industrial Electronics 2016; 99(6):1-12.

[10] He X, Yang K, Ji X, et al. Research on Vehicle Stability Control Strategy Based on Integrated-Electro-Hydraulic Brake System. SAE Technical Paper 
2017-01-1565, 2017.

[11] Zheng B, Anwar S. Yaw stability control of a steer-by-wire equipped vehicle via active front wheel steering. Mechatronics 2009; 19(6): 799-804.

[12] Beal C E, Gerdes J C. Model predictive control for vehicle stabilization at the limits of handling. IEEE Transactions on Control Systems Technology 2013; 21(4): 1258-1269.

[13] Ji X, Wu J, Zhao Y, et al. A new robust control method for active front steering considering the intention of the driver. Proceedings of the Institution of Mechanical Engineers, Part D: Journal of Automobile Engineering 2015; 229(4): 518-531.

[14] Yang X, Wang Z, Peng W. Coordinated control of AFS and DYC for vehicle handling and stability based on optimal guaranteed cost theory. Vehicle System Dynamics 2009; 47(1): 57-79.

[15] Ren B, Chen H, Zhao H, et al. MPC-based yaw stability control in in-wheel-motored EV via active front steering and motor torque distribution. Mechatronics 2016; 38: 103-114.

[16] Zhang H, Wang J. Vehicle lateral dynamics control through AFS/DYC and robust gain-scheduling approach. IEEE Transactions on Vehicular Technology 2016; 65(1): 489-494.

[17] Zhang H, Zhang X, Wang J. Robust gain-scheduling energy-to-peak control of vehicle lateral dynamics stabilization. Vehicle System Dynamics 2014; 52(3): 309-340.

[18] Jin X J, Yin G, Chen N. Gain-scheduled robust control for lateral stability of four-wheel-independent-drive electric vehicles via linear parameter-varying technique. Mechatronics 2015; 30:286-296.

[19] Aripin M K, Ghazali R, Sam Y M, et al. Uncertainty modelling and high performance robust controller for active front steering control. In: 2015 10th Asian Control Conference (ASCC); 2015. p. 1-6.

[20] He Z, Ji X. Nonlinear robust control of integrated vehicle dynamics. Vehicle System Dynamics 2012; 50(2): 247-280.

[21] Li B, Rakheja S, Feng Y. Enhancement of vehicle stability through integration of direct yaw moment and active rear steering. Proceedings of the Institution of Mechanical Engineers, Part D: Journal of Automobile Engineering 2015; 230(6): 830-840.

[22] Gibson T E, Crespo L G, Annaswamy A M. Adaptive control of hypersonic vehicles in the presence of modeling uncertainties. In: 2009 American control conference; 2009. p. 3178-3183.

[23] Yao J, Jiao Z, Ma D, et al. High-accuracy tracking control of hydraulic rotary actuators with modeling uncertainties. IEEE/ASME Transactions on Mechatronics 2014; 19(2): 633-641.

[24] Rashidi B, Esmaeilpour M, Homaeinezhad M R. Precise angular speed control of permanent magnet DC motors in presence of high modeling uncertainties via sliding mode observer-based model reference adaptive algorithm. Mechatronics 2015; 28: 79-95.

[25] Utkin V, Guldner J, Shi J. Sliding mode control in electro-mechanical systems. CRC press, 2009.

[26] Azar A T. Advances and applications in sliding mode control systems. Berlin: Springer; 2015.

[27] Sun T, Pei H, Pan Y, et al. Neural network-based sliding mode adaptive control for robot manipulators. Neurocomputing 2011; 74(14-15):2377-2384

[28] Hsu C F. Adaptive neural complementary sliding-mode control via functional-linked wavelet neural network. Engineering Applications of Artificial Intelligence 2013; 26(4):1221-1229.

[29] Liu Y H, Li T, Yang Y Y, et al. Estimation of tire-road friction coefficient based on combined APF-IEKF and iteration algorithm. Mechanical Systems and Signal Processing 2017; 88: 25-35

[30] Hashemi E, Khosravani S, Khajepour A, et al. Longitudinal vehicle state estimation using nonlinear and parameter-varying observers. Mechatronics 2017; 43: 28-39.

[31] Zhang H, Huang X, Wang J, et al. Robust energy-to-peak sideslip angle estimation with applications to ground vehicles. Mechatronics 2015; 30: 338-347.

[32] Ma B, Liu Y, Gao Y, et al. Estimation of vehicle sideslip angle based on steering torque. The International Journal of Advanced Manufacturing Technology 2016: 1-9.

[33] Pacejka H B, Bakker E. The magic formula tyre model. Vehicle system dynamics 1992; 21(S1): 1-18.

[34] Doumiati M, Victorino A, Lechner D, et al. Observers for vehicle tyre/road forces estimation: experimental validation. Vehicle System Dynamics 2010; 48(11): 1345-1378.

[35] Fei J, Ding H. Adaptive sliding mode control of dynamic system using RBF neural network. Nonlinear Dynamics 2012; 70(2): 1563-1573.

[36] Liu J. Radial Basis Function (RBF) neural network control for mechanical systems: design, analysis and Matlab simulation. Springer Science \& Business Media; 2013.

[37] Kang M, Li L, Li H, et al. Coordinated vehicle traction control based on engine torque and brake pressure under complicated road conditions. Vehicle System Dynamics 2012; 50(9): 1473-1494.

[38] Yuan L, Zhao H, Chen H, et al. Nonlinear MPC-based slip control for electric vehicles with vehicle safety constraints. Mechatronics 2016; 38 : 1-15. 
2017-11-20

\section{A vehicle stability control strategy with adaptive neural network sliding mode} theory based on system uncertainty approximation

Ji, Xuewu

Taylor \& Francis

Ji X, He X, Lv C, Liu Y, Wu J, A vehicle stability control strategy with adaptive neural network sliding mode theory based on system uncertainty approximation, Vehicle System Dynamics, Volume 56, 2018, Issue 6, pp. 923-946

http://dx.doi.org/10.1080/00423114.2017.1401100

Downloaded from Cranfield Library Services E-Repository 